\title{
EFFECT OF CHITOSAN GELATINIZATION TEMPERATURE ON WATER ABSORPTION AND WATER RETENTION OF CHITOSAN-BASED UREA FERTILIZER
}

\author{
N. Mohamad", A. H. Nor Nadiah, A. R. Jeefferie and D. Mohd Fairuz \\ Department of Engineering Materials, Faculty of Manufacturing Engineering, \\ Universiti Teknikal Malaysia Melaka \\ 76100 Durian Tunggal, Melaka, Malaysia \\ Email: noraiham@utem.edu.my \\ Phone: +606-555-2000; Fax: +606-331-6247
}

\begin{abstract}
Chitosan has a high potential to be blended together in urea fertilizer for slow release properties due to its unique polymeric cationic character and gel-forming properties. In agriculture, the slow release properties are normally indicated by the ability of urea fertilizer to absorb and retain water, since nitrogen is released to the environment once urea is in contact with water or enzyme. This paper investigates the effect of the chitosan content and gelatinization temperature on the physical properties of chitosanbased urea fertilizer. The chitosan content was varied from $0,3,5,7$ and $10 \mathrm{pph}$. Chitosan-based urea fertilizer was prepared through a direct wet mixing using a laboratory setup consisting of a beaker, magnetic stirrer and hotplate. The properties of chitosan-based urea fertilizer were compared at two different mixing temperatures which are $60^{\circ} \mathrm{C}$ and room temperature of $25 \pm 3^{\circ} \mathrm{C}$. The mixture was then dried in an oven at $60^{\circ} \mathrm{C}$ for 8 hours before being fabricated into pellets using a hydraulic hand presser. Water absorption and water retention analysis were carried out to measure the amount of water intake and the amount of water retained in the fertilizer. It was observed that mixing temperature has a negligible effect on the water retention of the fertilizers. However, gelatinization at room temperature resulted in fertilizers with better water absorption and water retention properties than the one gelatinized at $60^{\circ} \mathrm{C}$. These results were supported by X-ray diffraction (XRD) analysis conducted on the fertilizers. As a conclusion, the gelatinization temperature plays an important role in improving the water retention and water absorption capability of chitosan-based urea fertilizers. Furthermore, the presence of chitosan improved the crystallinity of the urea fertilizers, as indicated by XRD analysis.
\end{abstract}

Keywords: Chitosan; urea fertilizer; water retention; water absorption; X-ray diffraction.

\section{INTRODUCTION}

Fertilizer is a chemical compound containing three elements which are nitrogen, phosphorus and potassium. It is added to soil to release nutrients which are essential for the growth and development of crops (Yip et al., 2013). There are various types of fertilizer, either organic or synthetic. An important synthetic fertilizer is urea fertilizer, a major source of nitrogen nutrient for plants (Papangkorn et al., 2008). Unfortunately, the practical use of this fertilizer is not efficient due to the loss during application. Potential hazards of fertilizers to the environment have resulted in limitation of their use. The use of conventional fertilizers may lead to concentration levels that are too 
high for effective action. According to Chandra and Rustgi (1998), high concentration may produce undesirable side-effects either in the target area, which could lead to crop damage, or in the surrounding environment. Therefore, it is important to improve its performance during utilization. To address these problems, slow- and controlled-release technology in fertilizers is considered as a suitable method to efficiently supply nutrients to plants and decrease the loss and contamination. These technologies are designed for the fertilizer to release their nutrient contents gradually and to coincide with the nutrient requirement of a plant. These properties can be physically imparted in fertilizers by coating techniques on the granules of conventional fertilizers with various materials that reduce their dissolution rate (Wu, Liu, \& Liang, 2008; Hanafi, Eltaib, \& Ahmad, 2000). Slow-release fertilizers are made to release their nutrient contents gradually and to coincide with the nutrient requirement of a plant (Wu et al., 2008). The release and dissolution rates of water-soluble fertilizers depend on the coating materials. Recently, the use of slow-release fertilizer is a new trend to save fertilizer consumption and to minimize environmental pollution (Wu et al., 2008). According to Hart (1998), slow-release fertilizer reduces the toxicity of plants due to the slow release of nutrients into the soil solution. These materials are usually relatively expensive. Slow-release $\mathrm{N}$ fertilizers offer the potential for reduced $\mathrm{N}$ leaching if the $\mathrm{N}$ fertilizer release can be matched to crop demand. These fertilizers can be physically prepared by coating the granules of conventional fertilizers with various materials that reduce their dissolution rate. The release and dissolution rates of water-soluble fertilizers depend on the coating materials.

Nowadays, chitosan has attracted tremendous attention among researchers and its value has been proved by a number of studies conducted in this area quite recently. There are various studies regarding chitosan nanoparticles (Shi \& Tang, 2009), PVOH/chitosan-blended films (Park, Jun, \& Marsh, 2001), the mechanism of chitosan degradation by gamma and e-beam irradiation (Gryczka et al., 2009), FTIR studies of chitosan (Osman \& Arof, 2002; Pawlak \& Mucha, 2002; Kadir et al., 2010) as well as chitosan as a biosensor (Ibrahim et al., 2010). Chitosan-based urea fertilizer (CBUF) is $s$ biodegradable urea fertilizer developed to replace formaldehyde, which is now known to be a carcinogen for humans and animals. It is prone to cause watery eyes, burning sensations in the eyes, nose and throat, nausea, coughing, chest tightness, wheezing, skin rashes and allergic reactions in humans once exposed at certain level. Formaldehyde can affect people differently, so some people might be very sensitive while others may not have any noticeable reaction at the same level (United States of America Consumer Product Safety Commission, 2003; Committee on Toxicology, 1980; Çelik et. al., 2001; Bedino, 2004). In the worst case, it can cause nasal cancer when humans are exposed to a high amount of formaldehyde. Recently, formaldehyde has been widely used in agriculture technology as an anti-caking agent and slow release contributor as well as a non-biodegradable binder (Moore, Sansing, \& Williamson, 1976; Aarnio \& Martikainen, 1995; Shukla et al., 1991; Hojjatie, Abrams, \& Parham, 2004). It can dissolve in water and leach through the soil. Retention of this highly toxic substance has high potential to kill most of the soil organisms.

Our research team investigated the potential of chitosan as a biodegradable binder which is able to hold urea powder in a granular form, and as a slow release contributor. Urea fertilizer was chosen since it is a main source of nitrogen $(\mathrm{N})$ as a plant nutrient. In this paper, a process parameter which is gelatinization temperature is investigated. Two different temperatures were selected in order to study their effect on the properties of urea fertilizer pellets, and the findings were finally used to select the 
most effective temperature for cost and performance. This study involved a new approach, introducing chitosan into the fertilizer, where it was blended together with urea powder to impart slow release properties instead of coating an outer layer of the fertilizer, which is the approach most often used by other researchers (Riyajan et al., 2012; Han et al., 2009). The performance of chitosan-based urea fertilizer was measured from the amount of water absorption, water retention and structure crystallinity via XRD analysis.

\section{EXPERIMENTAL SETUP}

\section{Raw Materials}

Chitosan powders (419419 Aldrich) with particle sizes between $1.320 \mu \mathrm{m}$ and $590.102 \mu \mathrm{m}$ were purchased from Sigma Aldrich. Industrial grade bentonite with particle sizes of $1.320 \mu \mathrm{m}$ to $83.707 \mu \mathrm{m}$ and urea powder $(\mathrm{QReC})$ with particle sizes of $5 \mu \mathrm{m}-590.102 \mu \mathrm{m})$ and molecular weight of $60.06 \mathrm{~g} / \mathrm{mol}$ were supplied by a local company.

\section{Preparation of Chitosan-Based Urea Fertilizer}

Samples were prepared through the direct wet mixing method using an experimental setup which consisted of a beaker, hotplate and magnetic stirrer. Two different temperatures were investigated for binder synthesis; $60^{\circ} \mathrm{C}$ and room temperature of $25 \pm$ $3^{\circ} \mathrm{C}$. Firstly, chitosan and bentonite were weighed and placed in a beaker. Then, this was stirred in $20 \mathrm{ml}$ distilled water at either $60^{\circ} \mathrm{C}$ or room temperature $\left(\sim 25 \pm 3^{\circ} \mathrm{C}\right)$ using a magnetic stirrer at $300 \mathrm{rpm}$ until gelatinization state (this state is achieved when the thin watery liquid changes to a viscous liquid). Then, urea was added to the mixture and stirred until it was well blended for 20 minutes. Next, the mixture was dried in a conventional oven at $60^{\circ} \mathrm{C}$ for 8 hours. Further testing was performed on the samples after one day conditioned at room temperature. Five formulations of different chitosan content were prepared with constant amounts of water, urea and bentonite, as shown in Table 1. WT is the sample mixed at $60^{\circ} \mathrm{C}$ and $\mathrm{XT}$ represents binder mixing at room temperature, and the number denotes the amount of chitosan in pph.

Table 1. Formulation of chitosan-based urea fertilizers.

\begin{tabular}{|c|c|c|c|c|c|c|c|c|c|c|}
\hline $\begin{array}{l}\text { Sample } \\
\text { Code }\end{array}$ & WT0 & WT3 & WT5 & WT7 & WT10 & XT0 & XT3 & XT5 & XT7 & XT10 \\
\hline Urea (pph) & 100 & 100 & 100 & 100 & 100 & 100 & 100 & 100 & 100 & 100 \\
\hline $\begin{array}{l}\text { Chitosan } \\
\text { (pph) }\end{array}$ & 0 & 3 & 5 & 7 & 10 & 0 & 3 & 5 & 7 & 10 \\
\hline $\begin{array}{l}\text { Bentonite } \\
\text { (pph) }\end{array}$ & 1 & 1 & 1 & 1 & 1 & 1 & 1 & 1 & 1 & 1 \\
\hline Water (ml) & 20 & 20 & 20 & 20 & 20 & 20 & 20 & 20 & 20 & 20 \\
\hline
\end{tabular}

\section{Measuring Water Absorbency of CBUF}

Water absorption was used to determine the amount of water absorbed by the samples after a certain amount of time (Kakade et al., 2010). One (1) gram of CBUF was 
immersed in $20 \mathrm{ml}$ distilled water. The wetted sample was taken out after 30 seconds, placed on tissue paper to drain the excess water and weighed. Readings were taken every 30 seconds for 300 seconds.

\section{Measuring Water Retention of CBUF in Soil}

Two (2) grams of CBUF were mixed with $200 \mathrm{~g}$ of dry sandy soil and kept in a beaker. Then, $200 \mathrm{~g}$ of tap water were slowly added into the beaker and weighed $\left(\mathrm{W}_{1}\right)$. The beakers were left at room temperature and weighed every 4 days $\left(\mathrm{W}_{2}\right)$ until the $30^{\text {th }}$ day. The water retention ratio of soil (WR\%) was calculated using Eq. (1).

$$
\text { Water retention, WR }(\%)=\frac{W 2}{W_{1}} \times 100
$$

\section{X-Ray Diffraction (XRD) Measurement}

The structural characteristics of the films were studied with an X-ray diffractometer (XRD) Xpert Pro MPD from PANalytical using radiation of $\mathrm{CuK} \alpha$. Specimens were ground to powder form and placed tightly in a sample holder before testing. Analysis was carried out at $25^{\circ} \mathrm{C}$ with a degree of $2 \Theta$.

\section{RESULTS AND DISCUSSION}

\section{Water Absorbency of CBUF}

It is well known that urea will easily dissolve in water (Zangi, Zhou, \& Berne, 2009) and it normally takes around 270 seconds for urea to completely dissolve in water. Figure 1 shows the water absorption of all the samples. It is clearly observed that samples with high chitosan content (around 5 to $10 \mathrm{pph}$ ) show the highest water absorption rate during the first 30 seconds for both gelatinization temperatures. This phenomenon is a direct correlation with the increased hydrophilicity properties of the fertilizers with increasing chitosan content. The amount of absorbed water increases as the amount of the hydrophilic component increases in the compound (Nor Nadiah et al., 2013). Chitosan is a hydrophilic material whose hydrophilic polymers can absorb and retain liquids thousands of times their own weight (Wu, Liu, \& Liang, 2008). The more the chitosan loading ( 7 and $10 \mathrm{pph}$ ), the more water can be absorbed, and the higher the possibilities of samples to dissolve in water, faster than samples with low chitosan loading (0 and $3 \mathrm{pph}$ ). The weight gain of highly loaded CBUF with chitosan was because hydroxyl groups in the chitosan had attracted water molecules, increased the water uptake by the fertilizer and converted it into a swollen substance (Zhao et al., 2006) before diffusion took place. After 50 seconds, all the fertilizers started to show a reduction in their original weight with time, although the samples with 0,3 and $5 \mathrm{pph}$ displayed this condition at the very beginning of this analysis. The reduction in weight represents dissolution and diffusion from the fertilizers of components such as urea, bentonite and chitosan into the water. The largest contribution was from the urea content since urea makes up most of the fertilizers' weight: $~ 98 \%$ of the total weight.

During the first 150 seconds, there was still no clear specific pattern enabling us to draw a concrete conclusion regarding the influence of gelatinization temperatures on the absorption rate at this point. This was due to other variables that might be present during this study, including environment factors and surface reactivity. However, when 
the whole pattern was closely examined it was evident in most of the samples that gelatinization at $60^{\circ} \mathrm{C}$ yields the highest water absorption rate at the beginning and the fastest weight loss compared to gelatinization at room temperature.

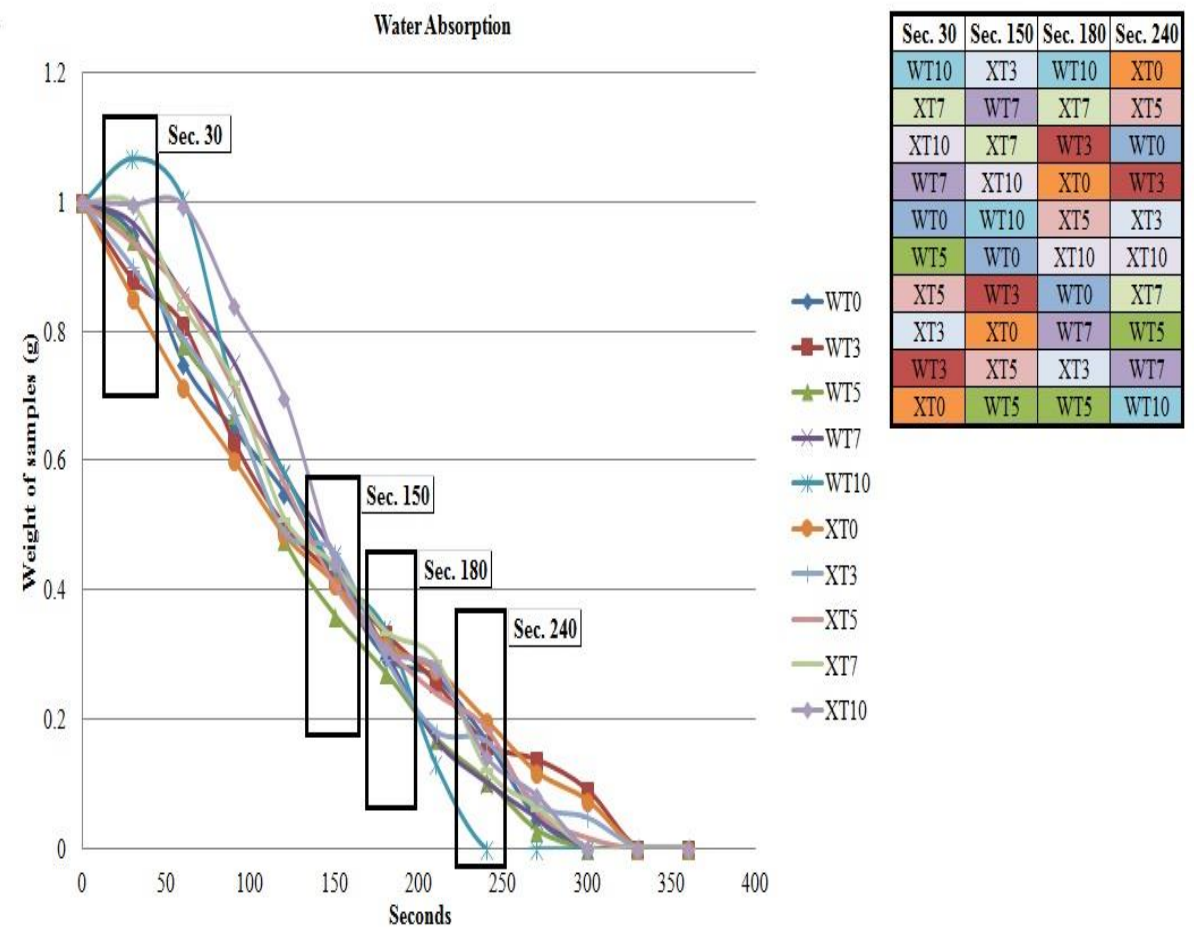

Figure 1. Water absorption for all samples (WT0, WT3, WT5, WT7, WT10, XT0, XT3, XT5, XT7, and XT10) in water for 360 seconds.

Figure 2 shows the physical appearance of the CBUF samples prepared by gelatinization at room temperature for $0,3,5,7$ and 10 pph chitosan after absorbing water for 180 seconds. These figures depict the effect of chitosan in accelerating the dissolution rate of CBUF.

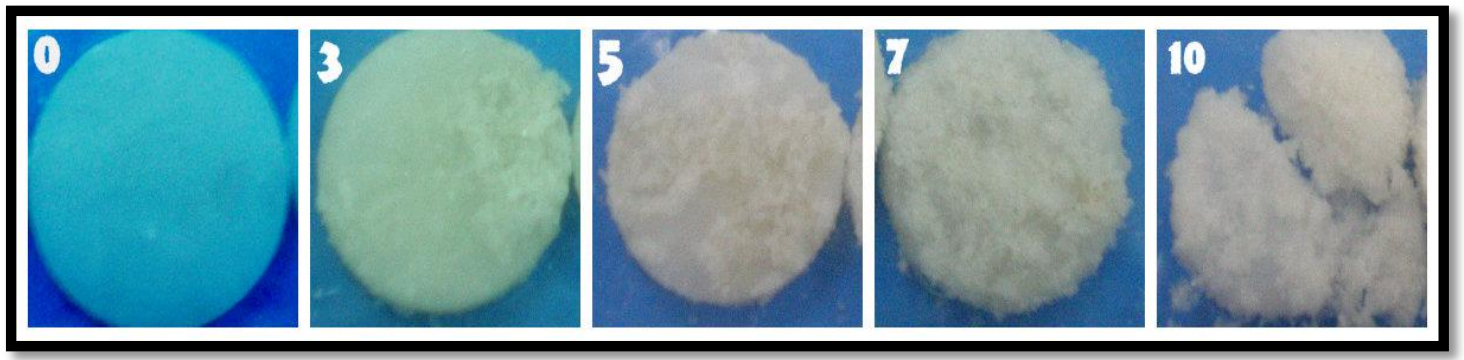

Figure 2. Physical diagram for samples of $0,3,5,7$, and 10 pph chitosan after 180 seconds absorbing water.

\section{Water Retention of CBUF in Soil}

Water absorbency is an important criterion for slow release fertilizers (Wu et al., 2008) since the presence of water will cause a gradual release of urea to the environment. However, water absorption should be assisted with water retention since the probability 
of fertilizers decomposing is very high without significant water retention ability. This is because the increase in permeability in swollen matrix apparently facilitates the urea to diffuse out very fast from the fertilizer. Furthermore, this is an important characteristic for agricultural activities in dry and desert regions for saving water, especially to sustain plant growth (Wu et al., 2008; Liang et al. 2007). In this study, water retention analysis was conducted for a period of 30 days. The water retention percentage of fertilizers for both gelatinization temperatures at different chitosan content is presented in Figure 3 and Table 2. In general, the water retention slowly decreased with time, except for the controlled samples which exhibited $0 \%$ at the $28^{\text {th }}$ day because no water was left after this point. The control was the soil without any samples. From Figure 3, it can be seen that there is no obvious difference in the pattern of water retention percentages for the different gelatinization temperatures.

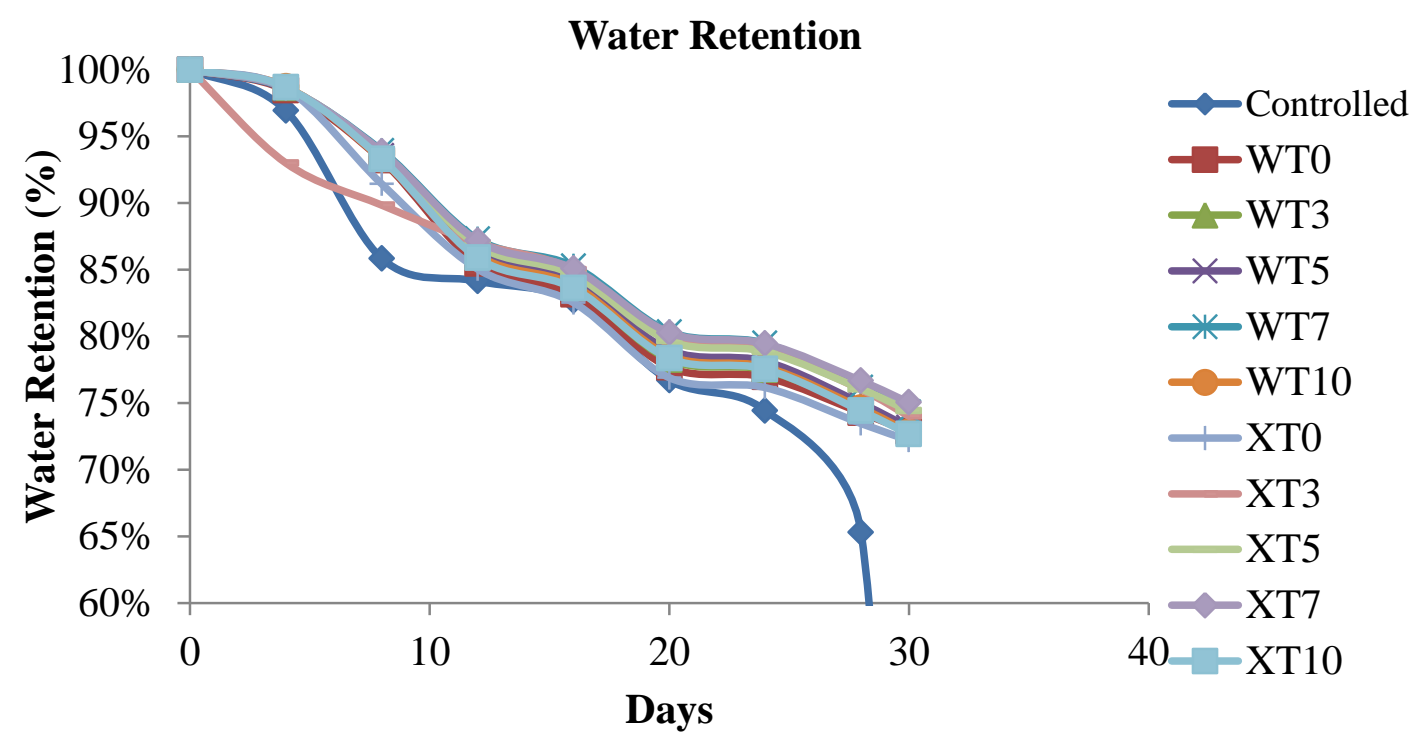

Figure 3. Water retention percentage for all samples (Controlled, WT0, WT3, WT5, WT7, WT10, XT0, XT3, XT5, XT7, and XT10)

Table 2. Detailed percentages of water retention

\begin{tabular}{c|cccccccccc}
\hline \multicolumn{2}{c}{$\begin{array}{c}\text { Days/ Sample } \\
\text { (day) }\end{array}$} & 0 & 4 & 8 & 12 & 16 & 20 & 24 & 28 & 30 \\
\hline \multirow{6}{*}{$\begin{array}{c}\text { Controlled } \\
\text { WT0 }\end{array}$} & 100 & 97 & 86 & 84 & 83 & 77 & 74 & 65 & 0 \\
& WT3 & 100 & 98 & 93 & 85 & 83 & 78 & 77 & 74 & 73 \\
& WT5 & 100 & 99 & 93 & 86 & 84 & 78 & 77 & 75 & 73 \\
Water & WT7 & 100 & 99 & 94 & 87 & 84 & 79 & 78 & 75 & 73 \\
retention & WT10 & 100 & 99 & 93 & 86 & 84 & 79 & 79 & 75 & 74 \\
& XT0 & 100 & 99 & 91 & 85 & 83 & 77 & 76 & 73 & 72 \\
& XT3 & 100 & 93 & 90 & 87 & 85 & 80 & 79 & 76 & 74 \\
& XT5 & 100 & 99 & 94 & 87 & 85 & 80 & 79 & 76 & 74 \\
& XT7 & 100 & 99 & 94 & 87 & 85 & 80 & 79 & 77 & 75 \\
& XT10 & 100 & 99 & 93 & 86 & 84 & 78 & 78 & 74 & 73 \\
\hline
\end{tabular}

However, when the exact value in Table 2 was taken into account, the CBUF with chitosan at around 3 to $7 \mathrm{pph}$ show the best water-retention capability. These 
samples exhibit a slightly higher ratio of water retention percentages during the $30^{\text {th }}$ day compared to other chitosan loadings and control samples. Besides, it is clear from this table that fertilizers prepared at room temperature have higher water retention than those prepared at $60^{\circ} \mathrm{C}$. This finding is in good agreement with another water absorption study (Wu et al., 2008) except that this study was apparently conducted with lower water contact, which is closer to actual application. Chitosan has a strong capability of absorbing water and retaining the water in its structure for a longer time before releasing its dissolved component into the surroundings, compared to fertilizers without chitosan. The water was stored in the fertilizer and slowly released with the decrease of soil moisture (Wu et al., 2008).

\section{X-Ray Diffraction (XRD) Analysis}

X-ray diffraction analysis was performed to show the crystalline and amorphous structure present in the CBUF samples compared with raw urea, chitosan and bentonite. Figure 4 shows the X-ray diffractogram of raw urea, chitosan, bentonite and CBUF gelatinized at $60^{\circ} \mathrm{C}$ (WT) and at room temperature (XT). In the diffractogram, urea shows a distinct peak which represents a crystalline powder, while a broader peak for chitosan shows its amorphous structure. Moreover, bentonite powder shows a broadening peak with a certain level of crystallinity. Both the CBUF samples, WT and $\mathrm{XT}$, exhibit crystallinity close to that of urea powder, with strong identical peaks at $22^{\circ}$, which point back to urea, except for a few shifted peaks which indicate the presence of bentonite in the samples.

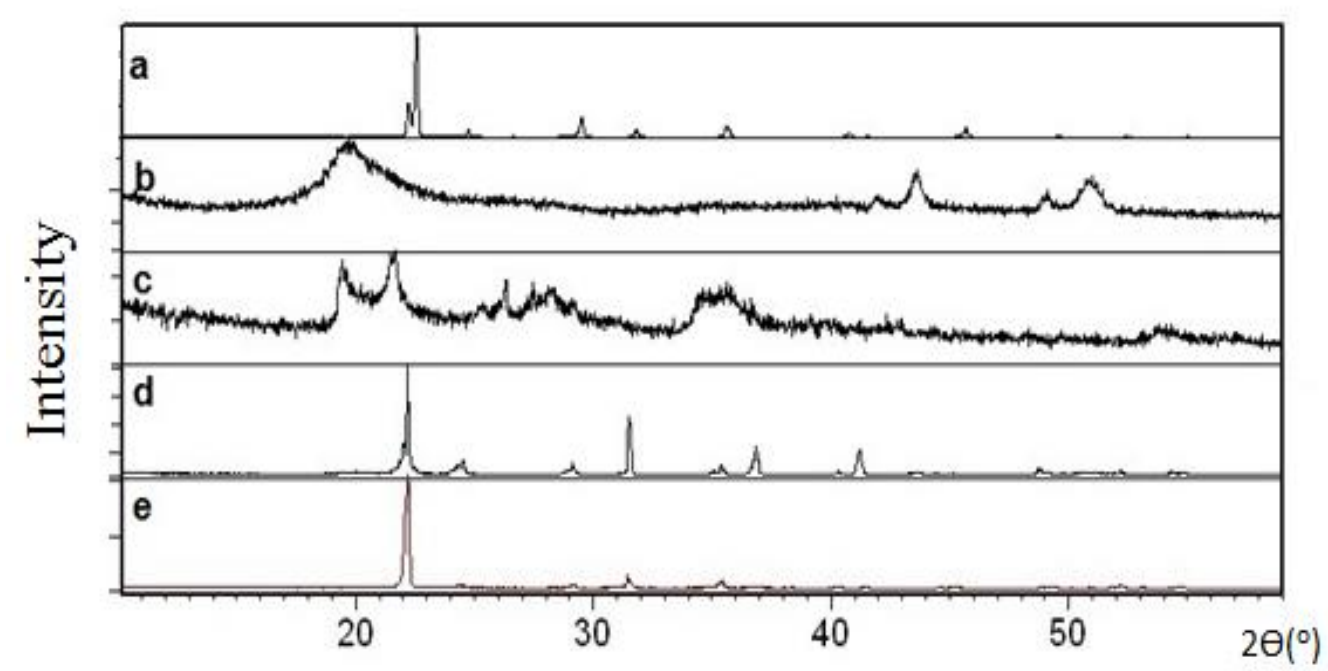

Figure 4. XRD patterns of (a) urea, (b) chitosan, (c) bentonite, (d) CBUF WT (chitosan 5pph), and (e) CBUF XT (chitosan 5pph).

When the peaks for WT and XT are closely examined, the XT samples show a slightly different pattern. This was postulated to be the effect of interaction between urea and chitosan, which is an amorphous organic polymeric material. This interaction is present to a greater extent in XT than in WT. This observation was in line with the better physical properties shown by XT compared with WT reported in other analyses. Incorporation of urea, bentonite and chitosan may result in physical or chemical interaction due to the existence of active hydroxyl groups in the chitosan structure that can act with urea or bentonite in an aqueous medium. This situation is similar to the 
research conducted by Han et al. (2009), when urea and chitosan were mixed together. According to Ionita and Iovu (2012), the formation of chitosan crystal units is dependent upon the dissolved solvents. In this case, the usage of distilled water as solvent normally results in a very weak crystallization or amorphous structure of chitosan. For slow release fertilizers, crystalline polymer is preferred because it tends to be stiffer, harder, and denser than amorphous polymers.

\section{CONCLUSIONS}

A chitosan-based urea fertilizer was successfully prepared using a wet mixing and compression technique. From the study it can be concluded that gelatinization at room temperature produced samples which exhibit a better water absorption and water retention capability than those gelatinized at $60^{\circ} \mathrm{C}$. The formulations which show a good balance between water absorption and water retention are CBUF filled with 3 to $7 \mathrm{pph}$ chitosan content. Both gelatinization temperatures produced CBUF with high crystallinity in its structure. Overall, the gelatinization process at room temperature indicates better performance as well as being cost effective. Furthermore, incorporation of chitosan in urea fertilizers has great potential that needs to be further investigated to produce a slow release fertilizer.

\section{ACKNOWLEDGMENTS}

The authors acknowledge the Ministry of Higher Education Malaysia and Universiti Teknikal Malaysia Melaka (UTeM) for granting the Long Term Research Grant Scheme (LRGS/2011/FKP/TK02/1 R00001) of Onebaja-Next Generation Green and Economical Urea (Green Processing : Biodegradable Urea Granules) and facilities to carry out this project. We wish to sincerely thank the Faculty of Manufacturing Engineering UTeM which provided expertise, equipment and technical assistance while we conducted our experiments.

\section{REFERENCES}

Aarnio, T. \& Martikainen, P. J. (1995). Mineralization of C and N nitrification in Scots Pine Forest soil treated with nitrogen fertilizers containing different proportions of urea and its slow-releasing derivative ureaformaldehyde. Soil Biology \& Biochemistry, 27(10), 1325-1331.

Chandra, R. \& Rustgi, R. (1998). Biodegradable polymer. Progress in Polymer Science, 23, 1273-1335.

Committee on Toxicology (1980). Formaldehyde - An assessment of its health effects. Board on Toxicology and Environmental Health Hazards, Assembly of Life Sciences, 4-29.

Gryczka, U., Dondi, D., Chmielewski, A. G., Migdal, W., Buttafava, A., \& Faucitano, A. (2009). The mechanism of chitosan degradation by gamma and e-beam irradation. Radiation Physics and Chemistry, 78(7-8), 543-548.

Zhao, G. H., Liu, Y, Fang, C. L., Zhang, M., Zhou, C. Q., \& Chen, Z. D. (2006). Water resistance, mechanical properties and biodegradability of methylatedcornstarch/poly(vinyl alcohol) blend film. Polymer Degradation and Stability, 91, 703-711.

Çelik, H. H., Sargon, M. F., Çelik, M. H., Usli, S. S., \& Çelik, T. H. (2001). A review of 
the health effects of formaldehyde toxicity. Retrieved from http://anatomidernegi.com/belge/formaldehit.pdf .

Han, X., Chen, S., \& Hu, X. (2009). Controlled-release fertilizer encapsulated by starch/polyvinyl alcohol coating. Journal of Desalination, 240, 21-26.

Hanafi, M. M., Eltaib, S. M., \& Ahmad, M. B. (2000). Physical and chemical characteristics of controlled release compound fertilizer. European Polymer Journal, 36, 2081-2088.

Hart, J. (1998). Fertilizer and lime materials. Fertilizer Guide, 52, 1-5.

Hojattie, M. M., Abrams, D. E., \& Parham, T. M. (2004). Liquid chromatographic determination of urea in water-soluble urea-formaldehyde fertilizer products and in aqueous urea solutions: collaborative study. Journal of AOAC International, 87(2), 346-351.

Ibrahim, M., Mahmoud, A. A., Osman, O., Refaat, A., \& El-Sayed, E. M. (2010). Molecular spectroscopic analysis of nano-chitosan blend as biosensor. Spectrochimica Acta Part A: Molecular and Biomolecular Spectroscopy, 77(4), 802-806.

Ionita, M. \& Iovu, H. (2012). Mechanical properties, urea diffusion, and cell cultural response of poly(vinyl alcohol)-chitosan bioartificial membranes via molecular modelling and experimental investigation. Composite Part B: Engineering, 43(5), 2464-2470.

Bedino, J.H. (2004). Formaldehyde exposure hazards and health effects: A comprehensive review for embalmers. An official publication of the Research and Education Department, The Champion Company - Springfield, OH 45501, 2633-2649. 2.

Kadir, M. F. Z., Aspanut, Z., Majid, S. R., \& Arof, A. K. (2010). FTIR studies of plasticized poly(vinyl alcohol)-chitosan blend doped with NH4NO3 polymer electrolyte membrane. Spectrochimia Acta Part A: Molecular and Biomolecular Spectroscopy. 78(3), 1068-1074.

Kakade, S. M., Mannur, V. S., Kardi, R. V., Ramani, K. B., \& Dhada, A. A. (2010). Evaluation of orally disintegrating tablets of sertraline. International Journal of Pharmaceutical Research \& Development, International Standard Serial No. 0974-9446, 1-7.

Liang, R., Liu, M., \& Wu, L. (2007). Controlled release NPK compound fertilizer with the function of water retention. Reactive \& Functional Polymers, 67, 769-779.

Moore, W. P., Sansing, J. E., \& Williamson, H. D. (1976). US3970625 Production of urea formaldehyde concentrate. Allied Chemical Corporation.

Nor Nadiah, A. H., Noraiham, M., Lum, Y. H., Mohd Fairuz, D., Mohd Asyadi, A., Mohd Haneesyah, C. H., Mohd Khairul, S. M. A., \& Azizah, S. (2013). The effect of chitosan content to physical and degradation properties of biodegradable urea fertilizer. Journal of Scientific \& Innovative Research, 2(5), 893-902.

Osman, Z. \& Arof, A. K. (2002). FTIR studies of chitosan acetate based polymer electrolytes. Thermochimica Acta, 48, 993-999.

Papangkorn, J., Isaraphan, C., Phinhongthong, S., Opaprakasit, M., \& Opaprakasit, V. (2008). Controlled-release material for urea fertilizer from polyactic acid. Advanced Materials Research, 55-57, 897-900.

Park, S. Y., Jun, S. T., \& Marsh, K. S. (2001). Physical properties of PVOH/chitosanblended films cast from different solvents. Food Hydrocolloids, 15(4-6), 499- 
502.

Pawlak, A. \& Mucha, M. (2002). Thermogravimetric and FTIR studies of chitosan blends. Thermochimica Acta, 396, 153-166.

Riyajan, S., Sasithornsonti, Y., \& Phinyocheep, P. (2012). Green natural rubber-gmodified starch for controlling urea release. Carbohydrate Polymers, 89, 251258.

Shi, L. E. \& Tang, Z. X. (2009). Adsorption of nuclease P1 on chitosan nano-particles. Brazilian Journal of Chemical Engineering, 26(02), 435-443.

Shukla, P. G., Rajagopalan, N., Bhaskar, C., \& Sivaram, S. (1991). Crosslinked starchurea formaldehyde (St-UF) as a hydrophilic matrix for encapsulation: studies in swelling and release of carbofuran. Journal of Controlled Release, 15, 153-166.

United States of America Consumer Product Safety Commission (2003). An update on formaldehyde. U.S. Consumer Product Safety Commission, 725, 2-12.

Wu, L., Liu, M., \& Liang, R. (2008). Preparation and properties of a double-coated slow-release NPK compound fertilizer with superabsorbent and water-retention. Bioresource Technology, 99, 547-554.

Yip, H. L., Azizah, S., Nona, M. M. M., Mohd Fairuz, D., Noraiham, M., Nadiah, H., \& Sian, M. S. (2013). Characterization of urea encapsulated by biodegradable starch-PVA-glycerol. Journal of Polymers and the Environment, 21(4), 10831087.

Zangi, R., Zhou, R., \& Berne, B. J. (2009). Urea's action on hydrophobic interactions. Journal of American Chemical Society, 131, 1535-1541. 